\title{
Factors affecting response to an invitation to attend for a health check
}

\author{
Margaret Thorogood, Angela Coulter, Lesley Jones, Patricia Yudkin, John Muir, David Mant
}

Imperial Cancer Research Fund General Practice Research Group, Department of Public Health and Primary Care, University of Oxford, Gibson Building, Radcliffe Infirmary, Oxford OX2 6HE.

$M$ Thorogood

L Jones

P Yudkin

J Muir

D Mant

Dealth Services

Research Unit,

Department of Public

Health and Primary

Care, University of

Care, University

Building, Radcliffe

Infirmary, Oxford

OX2 6HE.

A Coulter

Correspondence to:

Dr $M$ Thorogood

\begin{abstract}
Objective-To describe the characteristics of general practice patients who fail to respond to an invitation to attend for a health check, in relation to demographic variables, risk factor status, health status, and attitudes to behaviour modification.
\end{abstract}

Design-Postal questionnaire before invitation to attend a health check and subsequent record of attendance.

Setting-Five urban general practices in Bedfordshire, UK.

Subjects-A total of 2678 patients aged 35-64 years were invited for a health check in 1989-90.

Results-The number of patients who did not attend was low overall but was higher among men than women $(21 v 15 \%, \mathrm{p}<0 \cdot 001)$, and in unmarried than married patients $(24 v 16 \%$, $\mathbf{p}<0 \cdot 001)$. Failure to attend was also higher among people in manual than in non-manual occupations ( $21 v 15 \%, \mathrm{p}<0.001)$, in people living in rented accommodation than in homeowners (29 $v 16 \%, p<0.001)$, and in those without access to a car than in car users (27 $v 16 \%, p<0.001)$.

There was no difference in non-attendance rate according to age at completion of full time education. After adjustment for age, sex, marital state, and social class, the odds ratio for non-attendance was $1.74(95 \%$ confidence interval (CI) $1 \cdot 41,2 \cdot 14$ ) for smokers; $1.07(95 \%$ CI $0.76,1.51)$ for heavy drinkers; $1.91(95 \%$ CI $1.41,2.58)$ for those with a less healthy diet; and $1.50(95 \% \mathrm{CI} 1.09,2.07)$ for those who were obese. Patients who had visited their general practice more frequently and those who indicated a willingness to change their behaviour were significantly more likely to attend the health check. Conclusions-Health check attendance was lowest among patients who rarely attended the surgery and those who reported higher risk behaviour. Attendance was not, however, confined to the 'worried well'. Equal numbers of those with and without chest pain attended, as did at least three quarters of those in each risk group. This high rate of attendance reflects the time and effort invested in systematic recruitment. The development of a robust recruiting strategy is essential if substantial numbers, and particularly those at highest risk, are to be reached.

f Epidemiol Community Health 1993; 47: 224-228
British general practitioners are now offered financial incentives to provide routine health checks for their patients. Many practices have established clinics, administered by nurses where a number of screening checks are carried out and advice is offered on health related behaviour, such as smoking, diet, exercise, and alcohol consumption. ${ }^{1}$ The effectiveness of these checks in reducing risk, however, has not yet been shown. Whether this approach will reach those most in need of preventive advice has been questioned. The study of Waller et al indicated that attendance at these health check clinics administered by nurses was low and inversely related to the patients' cardiovascular risk. $^{2}$

The OXCHECK study is a randomised controlled trial of the effectiveness of nurseadministered health checks in helping patients to reduce their risk of heart disease, cancer, and stroke. Demographic, socioeconomic, and a variety of risk factor data were obtained by questionnaire from the study population before randomisation. Respondents were then randomised to be seen in one of four years of the trial, which is due to end in 1993. This, coincidentally, has provided an excellent opportunity to examine further the characteristics of those who do and do not respond to an invitation to attend for a health check.

\section{Methods}

All male and female patients aged between 35 and 64 years in five general practices in Luton and Dunstable were sent a health and lifestyle questionnaire before randomisation into the OXCHECK trial. The questionnaire included questions on health, risk factors, anxieties about health, and attitudes to making health promoting changes in lifestyle. Completed questionnaires were received from 11090 of the original list of 17965 patients taken from the family practitioner committee registers. After those patients who were known to have moved or died $(n=2327)$ had been excluded, the reponse rate was $72 \cdot 5 \%$. We had, however, previously estimated that because of inaccuracies in the sampling frame, the true response rate was $80 \cdot 3 \%{ }^{3}$

Questionnaire respondents were randomised to be invited for a health check in one of four years (mid 1989 to mid 1993). Recruitment is by mail or telephone organised by the OXCHECK nurses in each of the practices, or opportunistically by receptionists and general practitioners as patients attend the surgery. The nurses are aware of the importance of achieving the best possible response rate, and consequently put a considerable amount of effort into securing the patients' attendance. Up to three reminders are sent to those patients who do not attend. 
This paper reports the factors that affected the attendance of patients randomised to be invited for a health check in year one. The design of the trial and experience of the first year of health checks have been described in more detail previously. ${ }^{3}$ The full analysis of the trial data evaluating the effectiveness of health checks will not be available until completion of the fourth year in 1993.

\section{THE QUESTIONNAIRE}

The questionnaire, which was posted to patients before randomisation, was similar to that used in a previous health and lifestyle survey in the Oxford region. ${ }^{4}$ Additional questions included attitudes to behaviour modification and the World Health Organisation chest pain and claudication questionnaire. ${ }^{5}$ The survey included two indices of willingness to change behaviour harmful to health: subjects were asked whether they had previously attempted to change particular habits or behaviours and whether they wanted to change them.

\section{HEALTH CHECK RECRUITMENT}

Records were maintained of health check invitations by post and telephone. Opportunistic recruitment, as patients attended the practice, was initiated by labelling the appropriate medical records. Invitation could then be made by receptionists, doctors, or nurses. The frequency of

Table I Non-attendance rate in relation to sex, age, marital status, social class, housing tenure, education, and access to a car.

\begin{tabular}{|c|c|c|c|c|}
\hline & Attenders & Nom-attenders & $\begin{array}{l}\text { Non-attendanci } \\
\text { rate }\left({ }^{\circ}{ }^{\circ}\right)\end{array}$ & $95^{\circ} \circ \mathrm{CI}$ \\
\hline \multicolumn{5}{|l|}{$\overline{\text { Sex: }}$} \\
\hline Men & 987 & 262 & $21 \cdot 0$ & $18 \cdot 8,23 \cdot 3$ \\
\hline Women & 1218 & 211 & $\begin{array}{l}14 \cdot 8 \\
(\chi \bar{i}=17.3, p<0.001)\end{array}$ & 1) $13 \cdot 0,16 \cdot 6$ \\
\hline \multicolumn{5}{|l|}{ Age group: } \\
\hline $35-44$ & 812 & 189 & $18 \cdot 9$ & $16 \cdot 5,21 \cdot 3$ \\
\hline $45-54$ & 732 & 143 & $16 \cdot 3$ & $13 \cdot 9,18 \cdot 8$ \\
\hline $55-64$ & 661 & 141 & $\begin{array}{l}17 \cdot 6 \\
(\mathrm{NS})\end{array}$ & $15 \cdot 0,20 \cdot 2$ \\
\hline \multicolumn{5}{|l|}{ Marital status: } \\
\hline Married & 1774 & 335 & $15 \cdot 9$ & $14 \cdot 3,17 \cdot 5$ \\
\hline \multirow[t]{2}{*}{ Not married } & 386 & 123 & $24 \cdot 2$ & $20 \cdot 5,27 \cdot 9$ \\
\hline & & & $\left(\chi_{1}^{\frac{1}{1}}=18.9, p<0.001\right)$ & \\
\hline \multicolumn{5}{|l|}{ Social class: } \\
\hline I & 67 & 12 & $15 \cdot 2$ & $8 \cdot 1,25 \cdot 0$ \\
\hline II & 480 & 85 & $15 \cdot 0$ & $12 \cdot 1,17 \cdot 9$ \\
\hline IIIN & 530 & 88 & $14 \cdot 2$ & $11 \cdot 5,17 \cdot 0$ \\
\hline IIIM & 407 & 104 & $20 \cdot 4$ & $16 \cdot 9,23 \cdot 9$ \\
\hline IV & 286 & 73 & $20 \cdot 3$ & $16 \cdot 1,24 \cdot 5$ \\
\hline $\mathrm{V}$ & 65 & 25 & $27 \cdot 8$ & $18 \cdot 5,37 \cdot 1$ \\
\hline \multirow[t]{2}{*}{ Unclassified } & 217 & 55 & $20 \cdot 2$ & $18 \cdot 9,38 \cdot 2$ \\
\hline & & & $\left(x \frac{i}{1}\right.$ trend $=13 \cdot 5, p$ & $0 \cdot 001)$ \\
\hline \multicolumn{5}{|l|}{ Housing tenure: } \\
\hline Owner occupier & 1869 & 347 & $15 \cdot 7$ & $14 \cdot 2,17 \cdot 2$ \\
\hline Local authority tenant & 213 & 76 & $26 \cdot 3$ & $21 \cdot 2,31 \cdot 4$ \\
\hline \multirow{2}{*}{ Private tenant } & 85 & 44 & $34 \cdot 1$ & $25 \cdot 9,42 \cdot 3$ \\
\hline & & & $\left(x_{2}^{\frac{1}{2}}=44.7, p<0.001\right)$ & \\
\hline \multicolumn{5}{|l|}{ Age at finishing education: } \\
\hline 16 or older & 196 & 39 & $16 \cdot 6$ & $11 \cdot 8,21 \cdot 4$ \\
\hline 17 or 18 & 282 & 60 & $17 \cdot 5$ & $13 \cdot 5,21 \cdot 5$ \\
\hline 18 or younger & 1711 & 365 & $\begin{array}{l}17.6 \\
(\mathrm{NS})\end{array}$ & $16 \cdot 0,19 \cdot 2$ \\
\hline \multicolumn{5}{|l|}{ Employment status: } \\
\hline Employed & 1682 & 358 & $17 \cdot 5$ & $16 \cdot 7,18 \cdot 3$ \\
\hline Unemployed & 512 & 110 & $\begin{array}{l}17.7 \\
\text { (.NS) }\end{array}$ & $14 \cdot 7,20 \cdot 7$ \\
\hline \multicolumn{5}{|l|}{ Access to car: } \\
\hline Yes & 1923 & 368 & $16 \cdot 1$ & $14 \cdot 6,17 \cdot 6$ \\
\hline No & 270 & 98 & $\begin{array}{l}26 \cdot 6 \\
(x=2=23 \cdot 8\end{array}$ & $22 \cdot 1,31 \cdot 1$ \\
\hline
\end{tabular}

Numbers do not always add to the total $(2678)$ because of missing cases. these invitations was not documented so opportunistic recruitment was assumed if previous postal or telephone contact had not been documented.

CODING

Social class was coded from the respondents' replies to the postal questionnaire using the 1980 Classification of Occupations. ${ }^{6}$ A "healthy diet score", which scored positively for reported high fibre intake, low saturated fat intake, and high polyunsaturated fat intake, was constructed. Subjects were then divided into four diet groups representing quartiles of the diet score. The reported weekly intake of alcohol was classified as: no alcohol, moderate alcohol (less than 15 units a week for a woman or less than 20 units a week for a man), and excess alcohol ( 15 or more units a week for a woman or 20 or more units a week for a man). The body mass index (BMI, $\mathrm{kg} / \mathrm{m}^{2}$ ) was classified as: BMI less than 25 (acceptable); 25-29.9 (overweight); or 30 and over (obese). Reported levels of leisure time exercise were grouped as follows: vigorous exercise at least once a week (frequent); vigorous exercise at least once a month but not weekly (moderate); vigorous exercise less than once a month or never (sedentary).

ANALYSIS

Data were entered on a personal computer using dBASE software, and then transferred to a VAX cluster and analysed using the statistical package SPSS-X. Comparisons in non-attendance rates between different subgroups were made using the $\chi^{2}$ test. Adjusted odds ratios of non-attendance were estimated using the generalised interactive modelling (GLIM) statistical package. The statistical significance of each factor, after adjustment, was assessed by $x^{2}$ test, based on the improvement in the fit of the logistic model after the factor had been included in it.

\section{Results}

SLBJECTS

A total of 2777 patients were randomised to be invited for a health check during year one. Ninety nine of these patients were found to have moved away (88) or died (11). These have been excluded, leaving 2678, of whom 2205 attended for a health check, giving an attendance rate of $82.3 \%$.

SOCIAL STATUS

Table I shows the non-attendance rate in relation to demographic and social variables. The attendance rate was higher among women than men $\left(\chi_{1}^{2}=17 \cdot 3, p<0 \cdot 001\right)$. It was also higher in married patients $\left(\chi_{1}^{2}=18 \cdot 9, p<0 \cdot 001\right)$. Non-attendance was higher among patients in unskilled manual jobs, and tended to fall with increasing social class $\left(\chi_{\overline{1}}^{\frac{2}{1}}\right.$ trend $=13.5, p<0.001)$. Similarly, those who did not own houses $\left(\chi_{2}^{\frac{2}{2}}=44 \cdot 7, \mathrm{p}<0 \cdot 001\right)$ and patients who did not have access to a car $\left(\chi_{1}^{2}=23 \cdot 8\right.$, $\mathrm{p}<0.001)$ were less likely to attend. These observations were not independent; for instance $91.9 \%$ of owner-occupiers had access to a car, compared with only $56.2 \%$ of those in rented accommodation. There was no difference in attendance in relation to age or age at leaving full time education, nor according to employment status. 
HEALTH STATUS

The postal questionnaire included a number of questions about the respondents' health status and their self assessment of their health. Firstly, they were asked to rate their health status compared with others of the same age; and the percentage attendance by this rating is shown in table II. There was no consistent relationship, except that those in the extreme categories seemed less likely to attend, but the differences were not statistically significant. Secondly, subjects were asked to rate "how anxious" they were about their health and to assess their perceived "quality of life" on a 10 point scale, ranging from "no concern at all" to "extremely worried", and from "awful" to "wonderful" respectively. In each case there was no

Table II Non-attendance rate in relation to health status, visits to surgery, and diagnosis of angina or myocardial infarction.

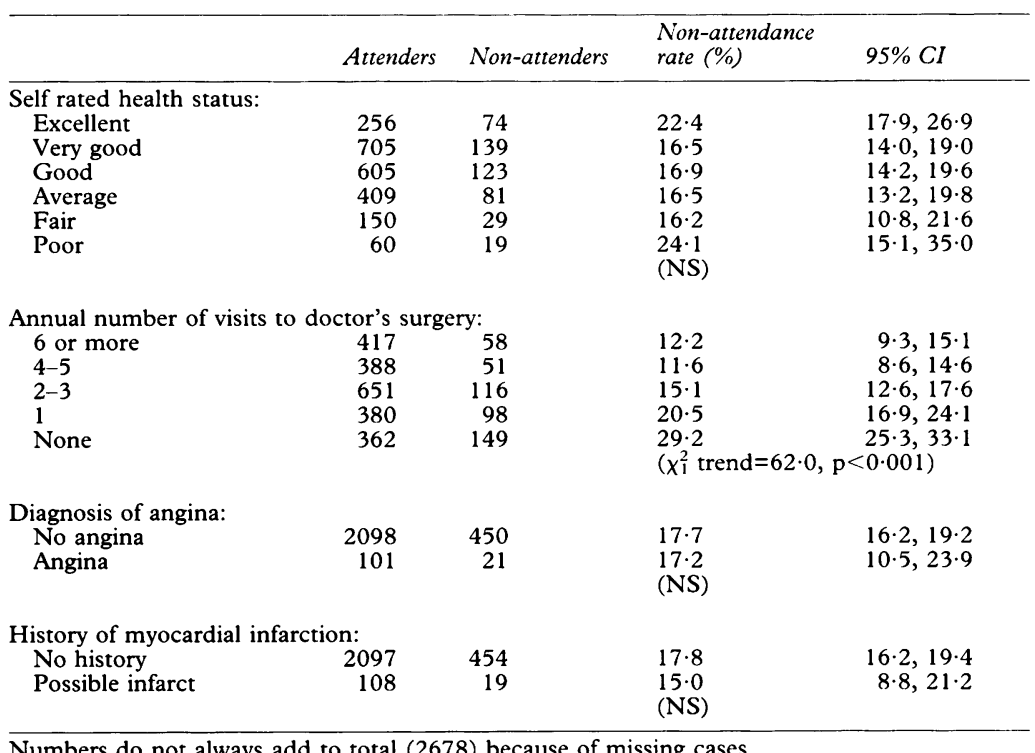

Table III Non-attendance rate and adjusted relative risk in relation to smoking status, alcohol consumption, diet score, body mass index, and exercise frequency.

\begin{tabular}{|c|c|c|c|c|c|}
\hline & Attenders & $\begin{array}{l}\text { Non- } \\
\text { attenders }\end{array}$ & $\begin{array}{l}\text { Non- } \\
\text { attendance } \\
\text { rate }(\%)\end{array}$ & $\begin{array}{l}\text { Odds ratio } \\
\text { (crude adjusted) }\end{array}$ & $\begin{array}{l}95 \% \text { CI for } \\
\text { adjusted } O R\end{array}$ \\
\hline \multicolumn{6}{|l|}{ Smoking: } \\
\hline Non-smokers & 1583 & 265 & $14 \cdot 3$ & & \\
\hline Smokers & 622 & 208 & $25 \cdot 1$ & $2 \cdot 0 \quad 1 \cdot 74$ & $\begin{array}{l}1.41,2.14 \\
\left(\chi_{1}^{2}=44.5, p<0.001\right)\end{array}$ \\
\hline \multicolumn{6}{|l|}{ Alcohol: } \\
\hline Non-drinkers & 437 & 107 & $19 \cdot 7$ & 1 & \\
\hline Moderate drinkers & 1406 & 258 & $15 \cdot 5$ & $0 \cdot 75,0 \cdot 76$ & $0.59,0.99$ \\
\hline Excessive drinkers & 267 & 84 & $23 \cdot 9$ & 1.251 .07 & $\begin{array}{l}0.76,1.51 \\
\left(\chi_{2}^{2}=16 \cdot 4, p<0.001\right)\end{array}$ \\
\hline \multicolumn{6}{|l|}{ Diet score: } \\
\hline 1 (best) & 623 & 88 & $12 \cdot 4$ & 1 & \\
\hline 2 & 533 & 94 & $15 \cdot 0$ & 1.251 .16 & $0.85,1.60$ \\
\hline 3 & 555 & 132 & $19 \cdot 2$ & 1.681 .51 & $1 \cdot 12,2 \cdot 04$ \\
\hline 4 (worst) & 460 & 151 & $24 \cdot 7$ & 2.321 .91 & $\begin{array}{l}1.41,2.58 \\
\left(\chi_{1}^{2} \text { trend }=36.9, p<0.001\right)\end{array}$ \\
\hline \multicolumn{6}{|l|}{ Body mass index: } \\
\hline $\begin{array}{l}\text { Acceptable } \\
\text { Overweight }\end{array}$ & $\begin{array}{r}1216 \\
761\end{array}$ & $\begin{array}{l}258 \\
141\end{array}$ & $\begin{array}{l}17 \cdot 5 \\
15 \cdot 6\end{array}$ & $\begin{array}{l}1 \\
0.87\end{array} 0 \cdot 83$ & \\
\hline $\begin{array}{l}\text { Overweight } \\
\text { Obese }\end{array}$ & 193 & $\begin{array}{r}141 \\
61\end{array}$ & $\begin{array}{l}15 \cdot 6 \\
24 \cdot 0\end{array}$ & $\begin{array}{l}0.870 .83 \\
1.49 \\
1.50\end{array}$ & $\begin{array}{l}0.60,1.07 \\
1.09,2.07\end{array}$ \\
\hline Obese & & & & & $\left(x_{2}^{2}=9 \cdot 7, p<0.001\right)$ \\
\hline \multicolumn{6}{|l|}{ Exercise: } \\
\hline Frequent & 202 & 48 & $19 \cdot 2$ & 1 & \\
\hline Moderate & 434 & 68 & 13.5 & 0.660 .68 & $0.45,4.03$ \\
\hline Sedentary & 1530 & 345 & $18 \cdot 4$ & 0.950 .96 & $\begin{array}{l}0.68,1.36 \\
\left(\chi_{2}^{2}=7 \cdot 0, p<0.05\right)\end{array}$ \\
\hline
\end{tabular}

evidence of any consistent relationship between these ratings and the likelihood of attending for a health check.

The prevalence of angina and myocardial infarction, as assessed from the questionnaire, was low and there was no evidence that such a diagnosis was related to attendance for a health check (table II). A total of 875 (33.2\%) subjects reported that they had a long standing illness or disability. There was no significant difference in the rate of non-attendance between these patients (142 non-attenders, $16 \cdot 2 \%$ ) and the 1760 without such an illness ( 326 non-attenders, $18 \cdot 5 \%$ ). There was, however, a clear relationship between attendance rate and number of previous visits to the surgery; more frequent visitors were more likely to attend for a health check $\left(\chi_{1}^{2}\right.$ trend $=62 \cdot 03$, $\mathrm{p}<0.001)$.

\section{RISK RELATED BEHAVIOUR}

Patients who have a lifestyle that is associated with an increased risk to their health (for example, smokers) are those at whom health checks should be principally targeted. Table III shows the nonattendance rate in relation to aspects of risk related behaviour. Attendance was significantly lower among smokers $\left(\chi_{1}^{2}=44.5, \mathrm{p}<0 \cdot 001\right)$, those with a high intake of alcohol $\left(\chi_{2}^{2}=16.4, p<0.001\right)$, and those who were obese $\left(\chi_{2}^{2}=9 \cdot 7, p<0.001\right)$. There was a clear and highly significant trend with each quartile of the "healthy diet score", such that the lowest attendance was among those with the worst diet, and the best was among those with the most healthy diet $\left(\chi_{1}^{2}\right.$ trend $\left.=37 \cdot 9, \mathrm{p}<0 \cdot 001\right)$. There was no consistent relationship between frequency of exercise and attendance, although attendance was better in the intermediate than extreme groups $\left(\chi_{2}^{2}=7 \cdot 0, p<0 \cdot 05\right)$.

Risk taking behaviour such as smoking or failing to exercise is related to other social characteristics. To assess the independent effect of risk taking behaviours on attendance, we examined the relationship between these and non-attendance after adjustment for age, sex, marital state, and social class (table III). The likelihood of nonattendance was still significantly associated with smoking $(\mathrm{p}<0.001)$, diet $(\mathrm{p}<0.001)$, and obesity $(p<0.01)$, but not with increased alcohol consumption or insufficient exercise.

\section{ATTITUDES TO BEHAVIOUR CHANGE IN HIGH RISK} GROUPS

Respondents were asked about their willingness to change health harming behaviour and whether or not they had previously attempted to do so. A minority in each risk group reported previous attempts to change their behaviour: $30 \cdot 2 \%$ of smokers, $25 \cdot 4 \%$ of heavy drinkers, $22 \cdot 1 \%$ of those who took little exercise, and $36.7 \%$ of those who were either overweight of whose diet was unhealthy. However, the majority in each of the risk groups, with the exception of the heavy drinkers, expressed a desire to reduce their level of risk: $74 \cdot 1 \%$ of the smokers wanted to give up; $58.8 \%$ who took little exercise said they would like to take more; and $54.4 \%$ in the overweight or unhealthy diet group said they would like to lose weight or change their diet. Only $31 \cdot 1 \%$ of the heavy drinkers expressed an interest in reducing their intake. 
Table IV shows the rate of non-attendance for the two indices of willingness to change behaviour. In each of the risk groups, apart from heavy drinkers, willingness to modify behaviour was associated with increased attendance. Previous attempts to increase exercise or change diet were also associated with a higher attendance rate.

Table IV Non-attendance rate for those in each risk group in relation to previous attempts at change and desire for change in behaviour.

\begin{tabular}{|c|c|c|c|c|}
\hline & Attenders & Non-attenders & $\begin{array}{l}\text { Non-attendance } \\
\text { rate }(\%)\end{array}$ & $95 \% C I$ \\
\hline \multicolumn{5}{|c|}{$\begin{array}{l}\text { Have tried to stop smoking? } \\
\text { (smokers } n=830 \text { ) }\end{array}$} \\
\hline $\begin{array}{l}\text { Yes } \\
\text { No }\end{array}$ & $\begin{array}{l}193 \\
424\end{array}$ & $\begin{array}{r}56 \\
152\end{array}$ & $\begin{array}{l}22 \cdot 5 \\
26 \cdot 4 \\
\text { (NS) }\end{array}$ & $\begin{array}{l}17 \cdot 3,27 \cdot 7 \\
22 \cdot 8,30 \cdot 0\end{array}$ \\
\hline \multicolumn{5}{|c|}{$\begin{array}{l}\text { Want to stop smoking? } \\
\text { (smokers } n=830 \text { ) }\end{array}$} \\
\hline $\begin{array}{l}\text { Yes } \\
\text { No }\end{array}$ & $\begin{array}{l}466 \\
144\end{array}$ & $\begin{array}{r}139 \\
68\end{array}$ & $\begin{array}{l}23 \cdot 0 \\
32 \cdot 1 \\
\left(\chi_{i}^{2}=6 \cdot 40 p<0.05\right)\end{array}$ & $\begin{array}{l}19 \cdot 6,26 \cdot 4 \\
25 \cdot 8,38 \cdot 4\end{array}$ \\
\hline \multicolumn{5}{|c|}{$\begin{array}{l}\text { Have tried to reduce alcohol intake? } \\
\text { (excess drinkers } n=351 \text { ) }\end{array}$} \\
\hline $\begin{array}{l}\text { Yes } \\
\text { No }\end{array}$ & $\begin{array}{r}65 \\
201\end{array}$ & $\begin{array}{l}24 \\
60\end{array}$ & $\begin{array}{l}27 \cdot 0 \\
23 \cdot 0 \\
\text { (NS) }\end{array}$ & $\begin{array}{l}17 \cdot 8,36 \cdot 2 \\
17 \cdot 9,28 \cdot 1\end{array}$ \\
\hline \multicolumn{5}{|c|}{$\begin{array}{l}\text { Want to reduce alcohol intake? } \\
\text { excess drinkers } n=351\end{array}$} \\
\hline $\begin{array}{l}\text { Yes } \\
\text { No }\end{array}$ & $\begin{array}{r}81 \\
184\end{array}$ & $\begin{array}{l}27 \\
55\end{array}$ & $\begin{array}{l}25 \cdot 0 \\
23 \cdot 0 \\
\text { (NS) }\end{array}$ & $\begin{array}{l}16 \cdot 8,33 \cdot 2 \\
17 \cdot 7,28 \cdot 3\end{array}$ \\
\hline \multicolumn{5}{|c|}{$\begin{array}{l}\text { Have tried to increase exercise? } \\
\text { (moderate exercise or sedentary } n=2377 \text { ) }\end{array}$} \\
\hline $\begin{array}{l}\text { Yes } \\
\text { No }\end{array}$ & $\begin{array}{r}447 \\
1507\end{array}$ & $\begin{array}{r}74 \\
333\end{array}$ & $\begin{array}{l}14 \cdot 2 \\
18 \cdot 1 \\
\left(x_{i}^{2}=4 \cdot 04, p<0 \cdot 05\right)\end{array}$ & $\begin{array}{l}11 \cdot 2,17 \cdot 2 \\
16 \cdot 3,19 \cdot 9\end{array}$ \\
\hline \multicolumn{5}{|c|}{$\begin{array}{l}\text { Want to increase exercise? } \\
\text { (moderate exercise or sedentary } n=2377 \text { ) }\end{array}$} \\
\hline $\begin{array}{l}\text { Yes } \\
\text { No }\end{array}$ & $\begin{array}{r}1166 \\
745\end{array}$ & $\begin{array}{l}196 \\
210\end{array}$ & $\begin{array}{l}14 \cdot 4 \\
22 \cdot 0 \\
\left(\chi_{i}^{2}=21 \cdot 9, p<0 \cdot 001\right)\end{array}$ & $\begin{array}{l}12 \cdot 6,16 \cdot 2 \\
19 \cdot 4,24 \cdot 6\end{array}$ \\
\hline \multicolumn{5}{|c|}{$\begin{array}{l}\text { Have tried to change diet or lose weight? } \\
\text { (overweight or unhealthy diet } n=1911 \text { ) }\end{array}$} \\
\hline $\begin{array}{l}\text { Yes } \\
\text { No }\end{array}$ & $\begin{array}{l}598 \\
935\end{array}$ & $\begin{array}{l}101 \\
271\end{array}$ & $\begin{array}{l}14 \cdot 4 \\
22 \cdot 5 \\
\left(\chi_{1}^{2}=17 \cdot 6, p<0 \cdot 001\right)\end{array}$ & $\begin{array}{l}11 \cdot 8,17 \cdot 0 \\
20 \cdot 1,24 \cdot 9\end{array}$ \\
\hline \multicolumn{5}{|c|}{$\begin{array}{l}\text { Want to change diet or lose weight } \\
\text { (overweight or unhealthy diet } n=1911 \text { ) }\end{array}$} \\
\hline $\begin{array}{l}\text { Yes } \\
\text { No }\end{array}$ & $\begin{array}{l}872 \\
646\end{array}$ & $\begin{array}{l}173 \\
194\end{array}$ & $\begin{array}{l}16 \cdot 6 \\
23 \cdot 1 \\
\left(\chi_{1}^{2}=12 \cdot 3, p<0 \cdot 001\right)\end{array}$ & $\begin{array}{l}14 \cdot 3,18 \cdot 7 \\
20 \cdot 3,25 \cdot 9\end{array}$ \\
\hline
\end{tabular}

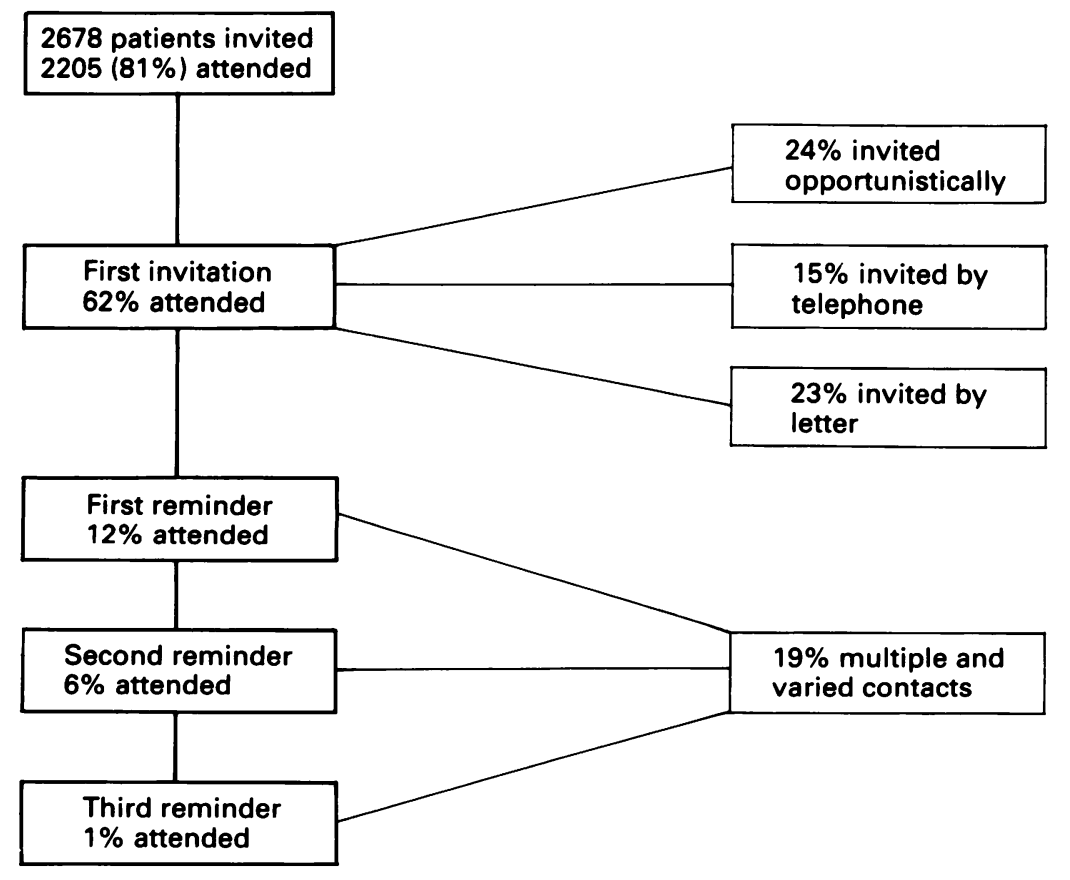

MODE OF RECRUITMENT

The figure illustrates the recruitment details. Three quarters of those who attended responded to a single opportunistic, postal, or telephone invitation. The last quarter required further reminders. However, a third reminder recruited only $1 \%$.

\section{Discussion}

There is a continuing debate about the most effective way to provide preventive care in general practice. The new terms and conditions of service for British general practitioners, which came into effect in $1990,^{7}$ aim to encourage a systematic approach to screening in which patients aged 16-74 years are invited to attend health checks. Critics of this approach have argued that it will involve time wasting consultations with the "worried well" who are least in need of preventive advice, and that it may lead to even greater social inequalities in health. ${ }^{8-10}$ This is not supported by our data. Firstly, patients who rated themselves more anxious about their health were not over represented among the attenders in year one of the OXCHECK trial. Secondly, there was no difference in attendance rates between those who rated their health as very good or excellent and those who said their health was below average. Thirdly, as we have already reported, ${ }^{3} 78 \%$ of the men and $68 \%$ of the women who attended the health checks needed specific advice or follow up. Our data suggest that with adequate recruitment of both sexes, wasting time with the worried well is not a problem.

In an earlier study of uptake of health checks administered by nurses in a practice in south Oxfordshire, ${ }^{2}$ we found higher attendance rates in those at lower risk. The pattern is repeated in this study to an even more marked degree. Nonattenders were more likely to be in the high risk groups (smokers, unhealthy diets, overweight, lower socioeconomic groups). Furthermore, those who were less well motivated to make lifestyle changes were less likely to attend.

Despite this unsatisfactory pattern of attendance at least $75 \%$ of the smokers, the heavy drinkers, those who were overweight, or those who took little exercise did attend. In the previous study less than half of the eligible patients had attended a health check within a five year period. Successful recruitment is a vital factor in a comprehensive strategy intending to reach a practice population. Opportunistic invitations require persistent effort and staff motivation and will not succeed alone. ${ }^{2}$ This method will not reach those who do not attend the surgery, a group identified in our data as those least likely to accept a health check invitation. Mailing standard invitation letters can be a quick exercise, especially if the recruiter has available printed name and address labels. Postal invitation is also the only option available for those who rarely consult and are not on the telephone. Telephone recruitment is time consuming and therefore expensive, but has an integral role when early appointments are underbooked. The system of integrating opportunistic, postal, and telephone recruitment has been consistently effective in recruiting $80 \%$ of subjects in the OXCHECK trial. 
The high rate of attendance was largely the result of the strenuous efforts of the nurses and receptionists to encourage uptake. A further significant factor in the OXCHECK trial is that invitations were sent only to those who had responded to an initial postal questionnaire. It is very likely that the rate of attendance at health checks would have been lower among those who had not responded to the questionnaire. Whether such high attendance rates could be sustained outside the context of a research study is uncertain. Others have reported encouraging results in response to strenuous efforts, ${ }^{11}$ but few practices succeeded in achieving a rigorously systematic approach to the organisation of prevention before the implementation of the 1990 general practioners' contract. ${ }^{12}$

That there is a need to be systematic in organising preventive programmes in general practice seems incontrovertible, ${ }^{211}$ but whether this should involve the provision of nurse administered health checks, or whether opportunistic case finding within general practice consultations is more appropriate, will become clearer with the final results of evaluative studies such as this trial. Health check attendance rates are process measures which may not be related to health outcomes. It has yet to be shown that screening and lifestyle advice provided in nurse run clinics is effective in achieving risk factor reduction and ultimately in reducing the burden of disease. In the absence of such evidence, the question of the most appropriate mode of organising prevention in general practice remains open.

We thank the OXCHECK study group for permission to use OXCHECK data for this report. We acknowledge the collaboration of the general practitioners involved and thank the OXCHECK nurses for their continued efforts. OXCHECK is funded by the Imperial Cancer Research Fund.

1 Fullard E, Fowler G, Gray J. Promoting prevention in primary care: controlled trial of low technology, low cost

approach. BMF 1987; 294: 1080-2.
2 Waller D, Agass M, Mant D, Coulter A, Fuller A, Jones L. Health checks in general practice: another example of inverse care? $B M F$ 1990; 300: 1115-8.

3 Imperial Cancer Research Fund OXCHECK Study Group. Prevalence of risk factors for heart disease in OXCHECK trial: implications for screening in primary care. BMF 1991; 302: 1057-60.

4 Coulter A. Lifestyles and social class: implications for primary care. $7 R$ Coll Gen Pract 1987; 37: 533-6.

5 Rose G, McCartney P, Reid D. Self administration of a questionnaire on chest pain and intermittent claudication. questionnaire on chest pain and inter
$B r$ P Prev Soc Med 1977; 31: 42-8.

6 Office of Population Censuses and Surveys. Classification of Office of Population Censuses and Surions. London: HMSO, 1980.
occupar

7 Department of Health. Terms of service for doctors in general practice. London: HMSO, 1989.

Pill R, French J, Harding K, Stott N. Invitation to attend a health check in a general practice setting: comparison of attenders and non-attenders. $\mathcal{F} R$ Coll Gen Pract 1988; 38: 53-56.

9 Tudor Hart J, Thomas C, Gibbons B, Edwards C, Tudor Hart M, Jones J, et al. Twenty five years of case finding and

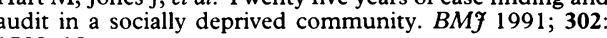
1509-13.

10 Griffiths J. A new GP contract for health promotion? Primary Health Care Management 1990; 1: 8-10.

11 Marsh G N, Channing D M. Narrowing the gap between a deprived and an endowed community. $B M F 1988 ; 296$ 173-6.

12 Coulter A, Schofield T. Prevention in general practice: the views of doctors in the Oxford region. Br f Gen Pract 1991; 41: 198-201. 